\title{
Situación actual en la prestación de los Servicios Públicos Domiciliarios y el problema de la desconexión.
}

\author{
The Current Situation Dealing With Home Utilities \\ and the Issue of Disconnection.
}

\section{Resumen:}

El presente artículo, producto de investigación titulada: "Situación actual en la prestación de los servicios públicos domiciliarios y el problema de la desconexión", en Medellín, enfatizando en el sector conocido como la Comuna Trece, pretende, sin duda alguna, visibilizar una problemática latente y con características de emergencia social, como es el caso de los llamados Desconectados de los Servicios Públicos Domiciliarios (SPD), especialmente del agua y de la luz. Al 2008 se registran más de 200.000 personas sin estos servicios básicos, por ende el presente articulo no sólo presentará y describirá el problema, sino las medidas institucionales tanto las que toma directamente la Alcaldía como las que asume la empresa prestadora del servicio, medidas que se han implementado para hacerle frente a esta situación, no muy publicitado pero, con claras consecuencias sociales que impactan negativamente los sectores populares, contrastando éstas medidas con las necesidades reales y posibilitando vislumbrar posibles alternativas.

Palabras Calve: desconectados, servicios públicos domiciliarios, derecho fundamental.

\begin{abstract}
:
This article, product of a research entitled "The Current Situation dealing with Home Utilities and the Issue of Disconnection," in Medellin, focused on the sector known as "Comuna Trece", aims at, without doubt, showing a latent issue that has social emergency characteristics, like it is the case of the socalled Disconnected of Home Utilities, regarding water and light. In 2008, there were more than 200,000 people who had no these basic services; therefore, this article not only will show and describe the issue, but the institutional measures made directly by the Mayor's Office, which is responsible for the service, measures which have been implemented in order to face such a situation, which has not been advertised fully, but with clear social consequences having a negative impact on the popular sectors, contrasting these measures with the real necessities and making possible to glimpse some solutions from different choices.
\end{abstract}

Keywords: Disconnected; Home Utilities and Fundamental Right.

'Sociólogo de la Universidad de Antioquia, Integrante de la Red Juvenil y su equipo de Investigación e intervención social en el tema de los Desconectados de los Servicios Públicos domiciliarios en Medellín. 


\section{Introducción}

\subsection{Contexto General de la Comuna 13}

La Comuna 13 está conformada en su totalidad por 23 barrios: El Pesebre, Blanquizal, Santa Rosa de Lima, Los Alcázares, Metropolitano, La Pradera, Juan XXIII, La Quiebra, Antonio Nariño, San Javier 1 y 2, 20 de Julio, El Salado, Nuevos Conquistadores, La independencia I, II y III, Belencito, El Corazón, Betania, Eduardo Santos, El Socorro y La Gabriela.

La comuna de San Javier tienen una población de 141.332 personas; el $48.5 \%$ de la población pertenece al estrato socioeconómico 1 , el $41.1 \%$ al estrato 2 , y el $10.3 \%$ a los estratos 3 y 4 , lo cual indica que un gran porcentaje (casi un 90\%) de la población se encuentra con en graves dificultades socioeconómicas ${ }^{2}$. El número de viviendas es de 32.137 que albergan 41.816 hogares, lo que implica un faltante de por lo menos 9.679 unidades de vivienda. La comuna presenta el más alto indicé de hacinamiento crítico en la ciudad, con 2.109 hogares en esta condición. Además de poseer 257 hogares en viviendas sin servicios públicos ubicadas todas en el estrato 1 y 86 hogares en viviendas inadecuadas ${ }^{4}$.

La población está compuesta por 74.835 mujeres (52,95\% del total) y 66.497 hombres (47.05\% del total), esto se explica entre otras cosas por el conflicto armado vivido hace 6 años que redujo la población masculina debido a la guerra. "La jefatura de hogar es ejercida en un $45 \%$ por las mujeres, muy similar a lo que ocurre en otros barrios populares de Medellín; esta modalidad crece a raíz de la viudez que dejó la ola de violencia, las separaciones, el madre solterismo y también a que los padres dejan de asumir todas o parte del rol que culturalmente se les asigna como padres de familia y en particular como proveedores ${ }^{\prime 5}$.

La densidad demográfica de la comuna se calcula de 182 habitantes por hectárea, lo que indica que cada habitante dispone de 5,5 metros cuadrados para vivir, mostrando los graves problemas de hacinamiento. La comuna tiene 879 manzanas y una densidad bruta de 18.364 habitantes por kilómetro cuadrado ${ }^{6}$. Es común la construcción de viviendas de baja calidad y en zonas de alto riesgo con un incremento de asentamientos subnormales, la insuficiencia sanitaria de las mismas, lo mismo que su informalidad e ilegalidad. Por otro lado se encuentra la insuficiencia en equipamientos educativos, en salud, en recreación y bibliotecas.

"... el análisis de vulnerabilidad de viviendas ubicadas en zonas de alto riesgo, determina que de las 9.929 viviendas existentes, 1.103 viviendas (11.11\%) se encuentran en alto riesgo no recuperable para ser habitadas, las cuales se encuentran asentadas en 825 predios. De ellos, el barrio que más viviendas aporta a este análisis es Nuevos Conquistadores con 537 viviendas $(49 \%)$, seguido del barrio el Salado con 312 viviendas (28\%), el barrio que menos aporta es Las Independencias con 254 viviendas (23\%)"

Un $18.87 \%$ de las viviendas de la comuna se encuentra amenazada ${ }^{8}$, El $4,48 \%$ se encuentran

392

AGo.USB Medellin-Colombia V. $9 \quad N^{\circ} 2 \quad$ PP. 294-600 Julio-Diciembre 2009 ISSN: 1657-8031 
amenazadas por deslizamiento, el 1,05 \% por inundación, el 4, $14 \%$ por avalancha y el 4,60 \% de las viviendas por otros factores.

Las características topográficas de algunas zonas importantes, permite definirlas como de "alto riesgo" y no urbanizables. Estos terrenos ubicados en las pendientes han sido objeto de invasiones por parte de grupos poblacionales provenientes de otros sectores urbanos o por procesos de desplazamiento y migraciones nacionales y regionales, especialmente del noroccidente y suroccidente antioqueño y del Urabá, y también del Chocó, por lo cual se concentra mucha población afrodescendiente.

Algunos de sus habitantes proceden de algunos barrios de la ciudad (principalmente de la zona Nororiental); que presionados por las precarias condiciones económicas, la violencia, amenazas por parte de grupos armados y las pocas posibilidades de adquisición de vivienda, se ven obligados a desplazarse a este sector de la ciudad, y muchos de ellos viven en ranchos de madera y zinc.

En la comuna la población ha tenido una gran capacidad organizativa y comunitaria y un sensible sentido de sus reivindicaciones sociales. Los nombres de sus barrios son elocuentes: Las Independencias, Nuevos Conquistadores, Corazón, 20 de Julio. Antes de que existiera allí cualquier expresión armada ilegal, y hasta hoy, la gente ha reclamado ser oída y atendida, por vías pacíficas.

El proceso de poblamiento de la comuna tuvo diversos orígenes: "Barrios como El Corazón, Belencito, Betania y El Salado, son asentamientos históricos que datan de finales del siglo XIX e inicios del XX, configurados a través del loteo de haciendas, con carácter inicialmente veredal. Entre las formas de producción legal del espacio cabe ubicar al barrio San Javier (construido inicialmente por la Cooperativa de Vivienda en lo que antes era la finca de Pepe Ángel), lo mismo que el barrio Belencito", también producto de urbanizaciones planificadas de carácter estatal. Asentamientos originados por "loteos piratas", hacia las décadas del 50-60, dan lugar a lo que luego serán los barrios Santa Rosa, La Pradera, Antonio Nariño, Belencito Segunda Parte y Veinte de Julio. Y por último ocupaciones por invasión, entre los años 79 y 81 , constituyen el origen de barrios como La Colina, Las Independencias 1, 2, 3 y Nuevos Conquistadores 1 y $2^{\prime \prime 10}$

\subsubsection{El Problema Socioeconómico de la Comuna.}

Educación: Deficiencia en cobertura y dotación de establecimientos e insuficiencia en número de educadores para preescolar, básica primaria y básica secundaria; altos niveles de analfabetismo, alfabetismo funcional, deserción, repitencia y hacinamiento escolar.

Salud: Limitación en cobertura y calidad de los servicios de salud; insuficiencia en prevención, promoción e intervención en salud; malnutrición -desnutrición- en niños y niñas y deficiencia alimentaría en escolares; altos niveles de contaminación ambiental y sanitaria. 
Equipamiento y Obras Públicas: Escasez de espacios públicos para la vida citadina: vulnerabilidad ambiental en zonas de alto riesgo, quebradas y basureros: deficiencia sistema de acueducto y alcantarillo, difícil accesibilidad a zonas de ladera, insuficiencia en equipamiento comunitario.

Economía: Altas tasas de desempleo. Subempleo (30\%), informalidad e ilegalidad económica, bajos ingresos, escasa promoción económica por ausencia de oportunidades laborales, estigmatización y marginalidad a los habitantes residenciados en la comuna"11 .

Los Ingresos: Con respecto a los ingresos por hogares, según la Encuesta de Condiciones de Vida (ECV) 2006 se estima que 17.302 jefes de hogar no reciben ingresos por trabajo y 9.690 hogares reciben un ingreso inferior a $\$ 400.000$ pesos, teniendo un promedio de ingresos por hogar para la comuna de $\$ 522.427$ pesos, que a lo sumo permite sobrevivir y es insuficiente para cubrir los gastos básicos de arriendo, pago de servicios públicos, alimentación, educación y salud de un $66 \%$ de la población. Esta situación se vuelve más crítica cuando se estima que en el $39 \%$ de los hogares la mujer es cabeza de hogar ${ }^{12}$, lo cual significa que la madre debe responder por todos los deberes y gastos del hogar, sólo con el ingreso que perciba por su trabajo, que generalmente es inestable e informal.

La población en edad de trabajar en la comuna 13 es de 107.985 personas de las cuales 22.435 se encuentran desempleadas, lo que indica una tasa de desempleo del $20,8 \%$ en ese sector de la ciudad. Teniendo presente este porcentaje tan alto de desempleo, se deduce que las limitaciones para el acceso al trabajo y la formación técnica y profesional en la comuna son muy altas. La tasa de trabajo informal se estima en un $63.9 \%$ de la población, que es el reporte de las personas que trabajan por cuenta propia.

De las personas que tienen algún tipo de trabajo, 31.429 son empleados u obreros particulares, 11.104 son trabajadores por cuenta propia y 2.439 son empleados domésticos. Esto implica que la mayoría de las personas que tienen este tipo de oficios, no están afiliadas a ningún sistema de seguridad social, ni afiliadas al régimen de pensiones.

Los índices de ingresos de sus habitantes, muestran que "el $60 \%$ de las familias tienen ingresos iguales a un salario mínimo legal vigente, lo que en términos reales condiciona la disponibilidad económica y la calidad de vida de los habitantes de la Comuna 13 y adicionalmente, la poca oferta de mano de obra calificada en nuestros barrios, imprime un alto grado de inestabilidad laboral para los y las trabajadores de nuestra Comuna, con todas las implicaciones económicas y sociales que esto conlleva, por lo que se hace necesario pensarnos el Desarrollo en términos de la instalación de escenarios de capacitación productiva, que posibilite negocios sostenibles con empleos estables y duraderos ${ }^{\prime \prime 3}$.

El Barrio Las Independencias: El Barrio Las Independencias está dividida en tres: la Independencias I, que comprende desde la carrera 108 hasta la 111, la II de la carrera 111 hasta la carrera 39, y la III desde la carrera 39 hasta el colegio El Refugio (carrera 1 14). Es decir 
los callejones comprendidas entre la carrera 108 hasta la 114 y desde la calle 34 hasta la $39^{a}$. La mayoría del barrio es de estrato 1, pero algunas casas que tienen por ejemplo una fachada más bonita, están clasificadas como estrato 2.

Limita al norte con el barrio Veinte de julio, al sur con El Corazón, al oriente con Belencito y al occidente con Nuevos Conquistadores. Al barrio se puede acceder por dos partes: la primera por el famoso sitio conocido como "La Torre", conocido por su historia de violencia armada pues este sitio permitió que los actores armados tuvieran el control del barrio y allí hubo grandes combates en la época del conflicto armado en el 2002, esta es la carrera $111 \mathrm{C}$ con calle 34 . Y la segunda por la cancha de microfútbol del barrio Veinte de Julio, por la que se llega a la base militar. Presenta unos altos niveles de pendientes, el terreno es muy quebrado y los espacios muy estrechos. El resto del barrio son callejones, que sin conocerlos corres el riesgo de perderse.

Alli la única presencia estatal que existe en la zona son el CAl de la Policía del Corazón (En los límites de la Independencia III, Nuevos Conquistadores y El Corazón) y la Base Militar "General Mario Montoya" (entre La Independencia I y la II). No existen instituciones de capacitación técnica o profesional, ni centros de salud (el más cercano es el centro de Salud de Villa Laura). Las Instituciones educativas se encuentran a las afueras del barrio, los niños asisten a la Escuela Betania y la de Belencito, los adolescentes y jóvenes al Colegio "El Refugio", y "La Independencia" en el barrio El Salado. Son muy pocos los hogares de bienestar familiar y hogares del "buen comienzo" para los más niños.

\section{La Metodologia Aplicada en el Trabajo}

La investigación tuvo un enfoque cualitativo con un énfasis especial en la Investigación Acción Participativa (IAP), en las interacciones con las comunidades, ya que la relación investigadorinvestigado fue muy horizontal y de reciprocidad de la información, es decir, no solamente se siguió la lógica de extraer información de los afectados para el beneficio propio de investigación, sino también que se apoyó a las comunidades para el conocimiento de su problema, y posibles soluciones, a través de procesos de reflexión conjunta que permitieron a los actores tomar una posición crítica frente a su realidad, e intentar movilizarse y transformar dichas situaciones que van en detrimento de su calidad de vida, y por ende de su dignidad como personas.

Respecto a los aspectos técnicos de recolección de la información, cabe señalar, en primer lugar:

- se privilegiaron fuentes primarias, y por dicha razón se adelantaron las siguientes actividades: a) Grupos focales con la participación de habitantes de la Comuna 13, que tuvieron residencia en la misma durante el período de la investigación, mayores de edad, y de diverso género; b) entrevistas semiestructuradas a profundidad, con líderes de las diversas organizaciones existentes en la comuna 13; c) entrevistas semiestructuradas a profundidad, con habitantes de 
la Comuna 13; d) encuestas aplicadas durante el Foro Social Medellín 2008. Además se realizaron más de 20 salidas de campo, en donde se hacían recorridos por el barrio, campañas de sensibilización, talleres, visitas domiciliarias, asambleas barriales, conversaciones informales, registro fotográfico e interlocutando con las personas y familias en la cotidianeidad de sus hogares.

- Se realizó una revisión y sistematización de la información secundaria, como la lectura de textos sobre la comuna y el barrio, el rastreo de prensa y del internet, la revisión de archivos institucionales de la ROC y otras organizaciones sociales y comunitarias, análisis de videos sobre los desconectados; Conocer volantes, panfletos y publicidad que circulaban gracias a las organizaciones. $Y$ se interpusieron además algunos derechos de petición para pedir información a las autoridades municipales.

\section{Resultados}

\section{1. ¿Cómo se fue configurando las Independencias?}

Asentamientos como La Independencia 1, 2 y 3 y Nuevos Conquistadores se iniciaron en forma esporádica y aislada como invasión en terrenos ubicados al occidente del barrio 20 de julio, posteriormente esta invasión se vuelve masiva en el año 80, en plena campaña para la alcaldía de Medellín del liberal Bernardo Guerra Serna. En un caso la religión, en otro el clientelismo político, y más comúnmente la necesidad vital de un espacio dónde vivir, han impulsado y promovido estas tomas de ocupación del espacio en zonas periféricas rezagadas en el proceso de desarrollo urbano configurando un sector deprimido que comienza a presentar problemas graves de servicios públicos.

El barrio fue fundado a finales de los años 70's, especialmente por gente proveniente de otros municipio de Antioquia y de otros barrios de la ciudad, que se asentaron en estos territorios debido a su situación de miseria, pues es de recordar que este barrio tiene su origen en una invasión, que al principio se llamo "Turbay Ayala", esto como estrategia para que no los sacaran de estos terrenos y se organizo un comité de acción comunal. "Nosotros hicimos los trazos y terminamos de acabar de dar los lotes e íbamos organizando a la gente para que se ubicaran". Luego en cabeza del secretario de Desarrollo Comunitario Benjamín Higuita Rivera les declararon el barrio en zona de alto riesgo, y esa cicatriz la han seguido los funcionarios que le siguieron a él. La legalización de la propiedad ha sido un asunto crítico en la vida del sector, aunque también ha sido un factor que ha contribuido a la movilización y la organización comunitaria ${ }^{6}$.

El proceso de poblamiento de ésta zona se origina a partir de una toma espontánea de tierra, de aproximadamente 1500 familias; muchas de las cuales se dedicaban al comercio informal en el centro de la ciudad, principalmente en la plaza de Cisneros, lugar donde confluían habitantes de diferentes barrios y zonas de la ciudad ${ }^{6}$. La mayoría de lotes que adquirió la población se 
hizo bajo la forma de apropiación, o por la compra de títulos de propiedad, a potentados ilegales (piratas) que tenían posesiones de tierra en otros barrios de la ciudad.

La solidaridad fue constante, predominaron las formas autónomas de solución de conflictos y se impusieron liderazgos naturales y organizaciones espontáneas mediante los cuales se logró acceder a servicios públicos (transporte, luz, agua, alcantarillado) y a recursos de equipamiento barrial. "A tanto ha llegado la comunidad que ya se han visto 80 familias que cedieron parte de su terreno a quienes viven en zona de riesgo" ${ }^{14}$.

"La historia que caracteriza el poblamiento de esta comuna, dado su carácter de invasión, cobra importancia a la hora de analizar las realidades sociales que se viven allí. De un lado los niveles de abandono y exclusión social en los han vivido por más de 25 años, reflejados en ausencia de inversión y políticas públicas que mejoren las condiciones habitacionales, económicas, sociales, culturales, ambientales y de inclusión política" ${ }^{15}$.

El sector antes era llamado la loma de los "Chenos" Arroyabe, debido a sus antiguos dueños. Estos terrenos eran de Nepomuceno Arroyabe y de Josefina Valencia Arroyabe, un lote de 400.000 metros cuadrados aproximadamente, estos eran de una de las tres familias más ricas de Medellín. Uno de los invasores comentó: "Cuando nosotros nos metimos aquí ellos no pagaban impuestos por estos terrenos".

"Los primeros en llegar se instalaron en la parte alta de la loma, porque desde las alturas era más fácil echarle piedra a los policías que empezaban a subir la cuesta con la tarea de derrumbar los ranchos". Muchas de las casas se construían en las noches para que las autoridades no se dieran cuenta, pero sin embargo en la mañana llegaba "la tomba" (policía) y les tumbaban los ranchos; estas peleas le dieron fama al sector. "La gente comenzó a llegar, cerró lotes y se dedico a construir, 'uno por la necesidad de vivienda iba comprando, y eso regalado. Cuarenta o cuarenta y cinco mil pesos un lote de terreno por estos lados '". Eran constantes los desalojos policivos, los cortes de energía, la lucha por el agua y las difíciles condiciones del terreno que aumentaban aún más con el manejo inadecuado del suelo y la falta de asistencia técnica contribuyó al desorden urbanístico.

El señor Martín Yepes dirigió la llegada de las primeras 15 familias. La policía las desalojó, pero las cosas no quedaron así. Estas mismas se encargaron de hacer más promoción y en una forma como explosiva, en el término de dos a tres semanas, la loma se lleno de familias. "La Independencia se convirtió en la invasión más grande en América Latina, pero cada muchacho tiene los recuerdos de una lucha casi sangrienta", comenta un joven: "mientras mi mamá llenaba las paredes de bahareque, nosotros con mi hermano nos agarrábamos a piedra con la policía".

Durante el proceso de conformación espontánea de este barrio, surgen líderes que buscan apoyo en la Administración Municipal para solucionar los problemas generados por la carencia de redes de servicios públicos y vías de acceso, tal como lo relata uno de ellos: "Cuando uno comienza una invasión, así como me toco a mí con Martín Yepes (quien fue asesinado), es bravo 
y le toca a uno luchar y de la magnitud como es Las Independencias: hicimos cabildos abiertos en el Concejo de Medellín, estuvimos en la mesa de la Asamblea Departamental y no le tomamos la Alcaldía a Bernardo Guerra Serna (hasta con megáfono y todo nos metimos)" 19 .

"A nosotros vinieron a atropellarnos y a tumbar los ranchos y nosotros volvimos exactamente el 15 de abril de 1979, llegando gente hasta de ltuango. Después nos informaron que iban a traer el ejército. En ese tiempo todavía se respetaban los signos patrios y nos conseguimos varias banderas de Colombia que se colocaron por todas las entradas de la invasión y pusimos un equipo en la parte de abajo del barrio, en cercanías al 20 de julio, en donde avisaban lo que estaba pasando a la comunidad y empezaban a sonar el himno nacional en varias partes a la vez, esta fue una acción de resistencia que permitió tomarse el sector y luego se pensó la toma de la Alcaldía. Luego de estas acciones el alcalde no volvió a mandar a "control de obras", que eran los que atropellaban a los invasores. Nos dejaron quietos pero nos tenían como "ladrones de terrenos ${ }^{\prime 20}$.

\subsection{Historia sobre los Servicios Públicos Domiciliarios (SPD):}

Los habitantes de manera creativa, al no existir infraestructura básica de servicios, se las ingeniaron para sobrevivir ante la difícil situación de no tener servicios. Así era como improvisaban fogones comunitarios de leña o petróleo para cocinar sus alimentos; además "Han construido senderos y barandas, tanques para el agua, un alcantarillado, malo según los del municipio y un acueducto que trae el agua desde el Corazón, para la mitad de las familias" ${ }^{21}$.

El abastecimiento de agua lo lograron primero extrayendo el líquido desde un pozo que existía en el 20 de Julio o de las quebradas que atravesaban la zona, pero tenían una deficiente calidad del agua. Después de instalados en el barrio "Nos fuimos y buscamos las redes de acueducto de EPM, rompimos el tubo madre y empezamos a llevar agua a nuestro barrio, que antes se llamaba La Invasión". "Con el acueducto comenzamos perforando las tuberías en la calle principal, después hicimos las acometidas y se le dio agua hasta el barrio El Salado con tubería RT-21 que es buena resistencia, cuando eso el presidente de la JAC era Luis Alfonso Restrepo" ${ }^{22}$ además de construir algunos tanques de almacenamiento de agua, que muchos lo llamaban el acueducto comunitario. Hasta hace aproximadamente 6 años la gente se surtía de estos tanques, con el beneficio de que sólo pagaban una cuota de mantenimiento al fontanero.

Con materiales desechables y de forma artesanal se le dio forma al alcantarillado, que fueron improvisados canales, que llevaban las aguas lluvias y las negras a los sumideros, pero muchos de ellos fueron al aire libre lo que perjudico la salud de muchas personas. Por ello tuvieron tropiezos con la Administración "Inicialmente, nosotros habíamos hecho 34 metros de alcantarillado, que no nos ha dejado continuar EPM, pero tampoco lo ha venido a hacer". El alcantarillado se lo pidieron a la secretaría de Obras Públicas, a Higiene Ambiental y a Desarrollo Comunitario, aunque "Reconocen que el alcantarillado que ejecutó la comunidad no está bien pegado, pero funciona sin embargo" ${ }^{24}$. 
Con la luz sucedió algo parecido, primero de contrabando y luego se legalizaron, ésta al principio la traían de alambres pelados, pegados a los transformadores de los barrios aledaños, como el 20 de Julio, y en muchas de las casas no habían contadores ni de energía ni de agua.

El periodo de legalización de los servicios se logró un poco la intervención del PRIMED en la zona entre los años 1993 y 1997, donde se mejoró un poco las condiciones en cuanto al entorno barrial y las viviendas. Se hicieron obras de mitigación de riesgo, más no de inversión social, como la reposición de las redes de acueducto y alcantarillado y de alumbrado público.

"Entre los años 1999 - 2002, se implementó una política pública por parte de EPM que tuvo un fuerte impacto en los sectores más pobres de la ciudad y en particular en la comuna 13, como fue implementar la regularización a través del cambio obligatorio de los contadores de energía y acueducto y su conexión legal a las Empresas Públicas, con el fin de combatir el robo de energía y también eliminar la existencia de pilas públicas que hacían las veces de acueductos comunitarios.

Esto forzó a muchas familias, que por años habían tenido como estrategia de supervivencia -en medio de la crisis social- el servicio de energía y acueducto por medio de conexiones ilegales o "de contrabando", tuvieran que pagar por los contadores y de paso empezar a hacer parte del sector formal que paga mes a mes las facturas por consumo de servicios públicos domiciliarios, lo que incrementó el costo de la canasta familiar y afectó los escasos ingresos de los hogares, sumado a los aumentos y a la progresiva eliminación de los subsidios para las estratos más pobres" ${ }^{\prime 25}$.

A finales del 2002 EPM se hizo presente para reparar los teléfonos y el alumbrado, especialmente averiados por causa de los continuos combates durante las operaciones militares del gobierno. Mucha de la gente llevaba meses pidiendo reparación de los servicios, pero los técnicos de las EPM no podían entrar a las Independencias, porque los amenazaban de que si lo hacían los mataban. Las milicias que ejercieron control en la zona no permitían que los empleados de EPM entraran al barrio porque podían desconectar a la gente que estaba debiendo sus facturas.

\subsection{Cómo nos encontramos hoy en materia de derechos sociales:}

"El gobierno debería ayudarnos, ningún gobierno hace nada por nosotros los necesitados". Que más que esta frase de un habitante del sector para resumir lo que se va a mostrar este acápite. Para empezar, lo primero que se quiere plantear frente a esta temática, es que fue un acuerdo de trabajo de las distintas organizaciones sociales y populares, a la hora de impulsar el FORO SOCIAL MEDELLIN 2008, que nosotros como ciudadanos del común tenemos 7 derechos básicos para tener una vida digna: alimentación, salud, educación, vivienda, servicios públicos, trabajo digno y recreación. 
El sistema económico imperante, pretende que todos los derechos también se rijan por la lógica del mercado limitando su acceso a quienes estén en capacidad de pagarlos en la medida que tenga con que comprarlos.

Para tratar de esclarecer un poco la situación, se tomó una muestra representativa de 113 encuestas para el barrio, con diez preguntas básicas para dar cuenta de los derechos fundamentales, de allí se obtuvo:

Ingresos: ¿̇la plata (ingresos económicos) le alcanza para comprar lo básico del mercado?, algunos respondieron que sí (un $24.7 \%$ de la población), mientras que buena parte, un $75.2 \%$ afirman no poder consumir una dieta balanceada, teniendo que obviar muchos productos de la canasta familiar a la hora de ir a mercar, si es que pueden. La gran mayoría de la población de las Independencias (95.5\%) sus ingresos no les alcanza para satisfacer las necesidades básicas de su familia, es decir que se sienten insatisfechos frente a su realidad y son los que más están sintiendo las consecuencias de la crisis y recesión económica del país.

Alimentación: En Las Independencias el problema del hambre no simplemente se puede nombrar, es algo con lo que se vive y sobrevive diariamente, tal vez imposible de cuantificarlo; allí sus habitantes no tienen los medios suficientes para poder comprar una canasta familiar básica y decente, muchas de las familias si desayunan no almuerzan, y si almuerzan no comen. El problema se complica mucho más los fines de semana, ¿̇porqué? Ya que a los menores que se encuentran estudiando, entre semana reciben un complemento alimentario en sus escuelas 0 colegios, pero cuando no son días estudiantiles, los costos del mercado del día suben. También los adultos mayores son víctimas de ésta situación, como muchos de ellos no trabajan les toca sobrevivir con lo que les den sus hijos, pero si la situación económica de los que ven por ellos no les resulta favorable, quedan totalmente indefensos y sin mucho que hacer, en el barrio no existe ningún restaurante comunitario que le sirva a la comunidad.

Queda por registrar, que la desnutrición le está ganando hoy la guerra a sus habitantes y todo porque faltan recursos económicos y por la falta de voluntad política de las autoridades locales para atender esta crisis alimentaria y humanitaria en la zona.

La reflexión que hace una Mujer mayor de edad, cabeza de familia de ésta zona, frente a su situación en relación a su percepción del desarrollo local es contundente, ella afirma: "mire todos esos parques que están construyendo y uno sin casi tener donde vivir o tener que comer, aguantando hambre y mandando los pelaos en ayunas pa'l colegio".

Pago de servicios Públicos: Solo a un $20.3 \%$ de los encuestados le alcanzan sus ingresos económicos para cancelar la cuenta de servicios públicos, aclarando que el $56.5 \%$ de los usuarios los pagan pero recortando el rubro para su alimentación; el resto, es decir un $79.6 \%$ no les alcanza el dinero para ello, explicando así, una de las razones por las que se cae muy frecuentemente en la situación de desconexión de los servicios públicos domiciliarios. 
Estabilidad laboral: Ahora bien, frente a la pregunta: ¿̇En su familia el trabajo es estable para todos? Sólo un 7\% nos dice que sí, y un alto margen del 93\% nos responde que no, desmintiendo lo planteado por los gobiernos locales y nacionales de la creación de nuevos puestos de trabajo con calidad, los que se logran encontrar, son de mala calidad y mal pagos, los llamados subempleados.

Atención en Salud: frente a la pregunta: ¿̇Le ha tocado a usted o a su familia hacer muchos trámites para que les atiendan en tratamientos de salud que no son de urgencia? Los encuestados respondieron: Si 69\% y No 31\%. Además algunos manifestaron que el Sisben muchas de las veces no cubre todos los medicamentos recetados por los médicos. Una cualidad de nuestro sistema de salud, son las demoras y los tramites que impiden que la población se pueda beneficiar completamente, a un $86 \%$ de los habitantes de las Independencias le ha tocado madrugar a hacer fila para pedir una cita en el sistema de salud o esperar o horas y horas detrás de un teléfono, sólo un 14\% se ha librado de este yugo.

Educación de los hijos: Un 96.5\% de los padres no cree en estar en capacidad económica para educar a sus hijos hasta niveles universitarios, ya que los ingresos no se lo permiten. Y por otra parte tanto los hijos como los padres no tienen el conocimiento de cómo ingresar a una Universidad Pública. Y un último factor es que los colegios ubicados en esta zona no poseen un buen nivel educativo que les permita competir con otros estudiantes de otros planteles que además los capacitan específicamente para presentar un examen de admisión y de un examen del Estado - ICFES.

La difícil situación del sector en materia económica, limita tanto a los jóvenes como a los adultos para que tengan las condiciones para terminar sus estudios; la posibilidad de acceder a una universidad es casi un sueño, ya que si pasan a las universidades públicas, no tienen recursos para cubrir los transportes y los gastos que implica ser un estudiante.

Recreación: ¿̇En los últimos años usted ha podido sacar vacaciones y viajar por las carreteras de Colombia hasta llegar a un bonito lugar a descansar de tanto trabajo? Respondieron afirmativo un $4.4 \%$ y negativo un $95.6 \%$. Esto nos demuestra que hoy en Colombia se podría pensar en la redistribución de la inversión pública pensando en ampliar la inversión de una mayor cantidad de recursos con planeación y de manera razonable y responsable, destinar más recursos para las personas, como subsidios para salud, vivienda, servicios públicos y educación.

Vivienda: El 70\% de sus habitantes posee casa propia, esto no necesariamente debido a su buena capacidad adquisitiva, sino a que fueron terrenos de invasión, que no les costó nada económicamente (aunque si fue dura la pelea), son viviendas apropiadas y usufructuadas, lo que no significa que las familias posean escrituras de su vivienda, son poseedores. De las propias encontramos que un $22 \%$ de ellas están en mal estado o son rancho de lata y tablas. El resto $(30 \%)$ pagan arriendo. El precio de estos arriendos oscila entre los $\$ 80.000$ y $\$ 120.000$ (el 63.5 de los arrendatarios), aunque también hay un porcentaje grande (27.2\%) que pagan más de 120.000 pesos mensuales por este concepto. 
Están declarados por la Administración Municipal, como zona de alto riesgo. La mayoría del barrio es perteneciente al estrato 1, pero también existen viviendas en estrato 2 . La cantidad de las casas es insuficiente para todos los hogares, además de ser muy pequeñas, sufren problemas de hacinamiento crítico. La calidad de las viviendas no es la mejor, los materiales no son los más recomendables, existen unas pendientes muy fuertes, y unas condiciones del terreno muy agrestes, lo que ha generado que en el invierno muchas casas se han venido al piso y sin forma de levantarla nuevamente.

Respecto a la vivienda digna, por ejemplo a varias familias el Sistema Municipal de Prevención y Atención de Desastres (SIMPAD) les ha dicho: 1. les ha dado la orden de evacuar éstas viviendas, por estar en zona de alto riesgo, pero sin soluciones concretas frente a su problemática, el SIMIPAD les ofrece un arriendo por tres meses periodo luego del cual quedan en una difícil situación de desamparo. 2. Les recomiendan que las casas las tienen que tumbar pero no reciben propuestas de reubicación. 3. A la gente le dicen que las viviendas están mal construidas pero no aportan dineros para los mejoramientos técnicos de las mismas.

"Los barrios Independencia I, II y III, El Salado y Nuevos Conquistadores, se encuentran clasificados en el segundo nivel de subnormalidad, de acuerdo con los criterios que Planeación tiene estipulados para Medellín. En general, se trata de barrios que no cumplen con todas las normas de urbanización, poseen áreas consideradas de alto riesgo, presentan servicios básicos deficitarios, viviendas construidas en materiales inestables o de desecho, familias que carecen de títulos de propiedad sobre el terreno" ${ }^{26}$.

En lo psicosocial: frente a la pregunta: ¿Le ha tocado padecer o ver desintegraciones familiares por culpa de la pobreza? un $60 \%$, nos respondió que sí, y un $40 \%$ que no. Este dato es importante, da cuenta de la situación socioeconómica puede llegar a afectar las relaciones en la vivienda, en la unidad familiar, tal como lo relata una joven del sector "muchas de las familias y de los hogares se separan por aquí, por problemas económicos".

\subsection{Situación Socioeconómica de las Familias.}

"Don Ernesto", no tiene trabajo actualmente, hace 5 meses está desempleado, es un trabajador de la construcción y los pavimentos, recibe diariamente entre ( un dólar equivale en promedio a 2.000 mil pesos colombianos) 25.000 y 18.000 pesos, cuando hay trabajo. De esto depende toda la familia, por lo que sus ingresos son insuficientes, además de no tener un trabajo estable. En la vivienda de doña Evangelina, 2 personas de la casa laboran y ganan más o menos el mínimo cada una es decir un promedio de 900,000 pesos; lo grave de este caso es que en la familia hay 17 integrantes, es decir, que a cada uno le corresponde gastarse 50.000 mensuales, por lo que el dinero no les alcanza para tanta gente y sobre todo los menores de edad que requieren más inversión para la educación y todo lo que esto acarrea. 
Estos casos dan cuenta de la grave problemática socioeconómica por la que atraviesan estas familias, y nos da una idea general del contexto de pobreza en el que viven éstas personas.

Pago de servicios públicos, en los talleres realizados con la comunidad, es reiterativo el hecho que a la mayoría de la población no le alcanza con qué pagar la cuenta de servicios, ellos prefieren invertir en comida y educación para sus hijos, que cancelar la cuenta de servicios que envían las Empresas Públicas de Medellín (EPM). Gran parte de la comunidad considera muy altos el costo de los servicios, a sabiendas que en la zona predomina el estrato 1; por eso, ante ésta situación de exclusión social, mucha de la comunidad se ha hecho consciente y han generado un movimiento de protesta, manifestando públicamente y exigiendo que los Servicios Públicos Domiciliarios (SPD) se consideren como un derecho humano fundamental generando así, algunos procesos de exigibilidad de sus derechos como ciudadanos.

Dentro de las encuestas se pudo encontrar que el 52\% de la población muestra, tenían cómo ingreso mensual un salario mínimo, aproximadamente $\$ 500.000$ pesos al mes, unos 250 dólares al mes aproximadamente, otro $40 \%$ sus ingresos eran inferiores a un salario mínimo y solamente el $8 \%$ recibían dos salarios mínimos. Como se puede apreciar la gran mayoría de la población sufre problemas con la falta de ingresos. Sin embargo, tal como lo plantea una ama de casa, "a pesar de que mi esposo tiene un trabajo fijo por el mínimo, no nos alcanza es para nada"

Muchos personas solo trabajan medio tiempo para el sostenimiento de toda su familia, pero con el agravante de que son trabajos informales. La inestabilidad laboral se hace evidente en estas familias, por lo cual prefieren priorizar sus ingresos para la alimentación. Otros y otras tienen empleo de oficios varios en casas de familia de Laureles, o en fábricas. Es común también el trabajo por días en el servicio domestico. Están también los que trabajan independientemente en lo que les resulte, dependiendo del día, a veces se ganan unos 20.000 pesos por la labor del día, cuando ésta resulta, unos 10 dólares el día, pero no es suficiente, sobre todo los vendedores ambulantes, o vendedores de la calle, pues son subempleos muy inestables, a esto se le agrega el ideal de la recuperación del espacio público lo que genera un conflicto permanente entre ésta formar de trabajar y la administración municipal que les persigue, reteniéndoles su mercancía y en algunos casos ésta termina perdiéndose.

Casos en el que un sólo miembro de la familia trabaja, pero sólo por algunos días a la semana, no se trata de trabajos estables, es por temporadas, como empleadas domésticos, trabajos de plomería y albañilería, pintores de brocha gorda, reparando cosas eléctricas, como celadores y los llamados "paleros". "Antes trabajaba, pero ya no tengo algo fijo, a veces lo que resulta. La hija mayor trabaja tres días en un bar, que por día se puede ganar 15.000 pesos, con eso nos mantenemos todos en la casa".

El trabajo en el comercio informal, entiéndase ventas de la calle, también es muy frecuente, algunos venden mazamorra, o ventas de algunas cosas en pequeñas tiendas de esquina que sólo dan para la comida y se pueden estar ganando entre 5.000 a 10.000 o 15.000 diarios, lo 
que no le alcanza para mantener su, por lo general, amplia familia. Otros viven de la venta de reciclaje, lo que hace que las ganancias sean muy pocas e inestables.

Los sueldos de estos tipos de trabajo no son bien pagos en la ciudad, muchos de los habitantes a veces no llegan a ganarse un mínimo, por lo que su situación es bastante precaria, debido a su bajo nivel educativo les es difícil acceder a mejores empleos, y tienen que resignarse con lo que encuentren. "No tengo un empleo fijo y toda mi familia depende de mi exclusivamente".

Mucho se habla de la violencia de la comuna 13, sobre su importancia, sobre los actores, sobre el control territorial, pero se ha olvidado hablar especialmente de una violencia más profunda, de tipo estructural, que son las precarias condiciones socioeconómicas de la población que se refleja especialmente, en los altos índices de pobreza, desnutrición, baja calidad de vida, hacinamiento crítico, falta de servicios públicos y de amoblamiento urbano, que se presenta por la desigualdad económica, política y social, por parte de un modelo de ciudad excluyente.

\subsection{Los Servicios Públicos Domiciliarios (SPD).}

\subsubsection{Descripción general y principales problemáticas con los SPD}

El barrio posee servicios de forma legal desde hace aproximadamente 15 años, los primeros quince fue una lucha por la sobrevivencia y de confrontación directa con las Empresas de Servicios Públicos de Medellín (EPM) y la Alcaldía Municipal, siendo los servicios de mala calidad. Con el paso del tiempo fueron mejorando pero a su vez fueron incrementándose sus costos, es decir que el problema ya no era con el acceso a los SPD, sino con su prestación, debido a las altas tarifas que muchas de las veces se hacían impagables o las familias tenían que dejar de comer bien por pagar las facturas. El barrio pertenece al ciclo 8, lo que significa que la lectura de contadores se realiza entre el 22 y 24 de cada mes y es precisamente esos días donde más se realizan acciones de desconexión.

Dentro de la muestra que se realizo se pudo establecer que a un 34\% de la población el precio de las facturas mensualmente era entre $\$ 50.000$ y 75.000 (entre 25 y 33 dólares aproximadamente), un $26.8 \%$ entre $\$ 76.000$ y 100.000 (entre 33 y 50 dólares aproximadamente), un $16.1 \%$ el valor oscila entre $\$ 101.000$ y $\$ 125.000$ (entre los 50 y los 63 dólares aproximadamente); el 12.5\% entre $\$ 126.000$ y $\$ 150.000$ (entre los 64 y 73 dólares aproximadamente), y por ultimo un $10.7 \%$ la cuenta es superior a los $\$ 151.000$ pesos más de 74 dólares al mes aproximadamente). Y sacando el promedio general del total de los valores facturados nos da la cifra de $\$ 97.000$ (48 dólares aproximadamente como promedio mesual), o sea que las facturas se les está devorando en promedio un $27.7 \%$ del total de sus entradas económicas, si tenemos en cuenta que el promedio de ingresos es de $\$ 350.000$ por familia (175 dólares al mes aproximadamente), cuando en algunos países, donde los Servicios Públicos (SPD) son considerados derechos humanos fundamentales, la población sólo destina entre el 6 y 10\% de sus ingresos para este rubro. 
Para el agua potable se abastecen del tanque de agua de EPM ubicado en el barrio del Corazón, específicamente en la calle 34ad $N^{\circ} 16 f-50$. Y una minoría todavía hace uso del anterior acueducto comunitario.

El alcantarillado no tiene buena calidad, es uno de los graves problemas que se presenta en la comunidad ya que no existe una división entre aguas negras y aguas lluvias, por lo tanto a veces los malos olores de los vertimientos, especialmente en las noches lo que afecta la salud de los pobladores especialmente la de los niños, a algunos de ellos les han aparecido ronchas o granos en su cuerpo cuando juegan muy cercanos a estas alcantarillas.

Respecto a la energía se tiene un buen servicio en cuanto a lo técnico y de calidad, todas las viviendas poseen conexión a la energía, pero no todos la pueden disfrutar, que son los que encuentran cortados. A ellos o se alumbran con velas o se las pasa un vecino o utilizan el contrabando, los que se deciden por esta última opción reciben la energía pero sin ningún tipo de regulación, por lo que la energía varia sus voltajes o son muy bajitos, entonces cuando prenden un electrodoméstico les toca apagar el fogón o los focos; su calidad es realmente mala y además corren el riesgo de que se les quemen sus pocos aparatos eléctricos que posean en casa.

El sistema prepago de energía, se ha venido implementando en la comuna y en barrio desde octubre de 2007, muchos de los habitantes decidieron acogerse a esta estrategia de mercado, ya que les representaba una solución inmediata, pues pasaban de ser desconectados a conectados. Pero con el tiempo se dieron cuenta de que el servicio les salía más caro y muchas veces se quedaban en la mañana sin con qué hacer el desayuno, generándoles muchos más problema. Ésta es una de esas percepciones: "A mí el prepago de energía, me parece un total robo, además de que las EPM le está mintiendo a la gente con las cifras, ya que ya no figuramos como desconectados y ellos se ufanan de estar reduciendo el número, yo lo por lo menos todavía me considero desconectado" ${ }^{\prime 2}$.

Frente al alumbrado público hay una queja constante de la comunidad es que no entienden porque tienen que pagar la luz de afuera de sus casas, cuando muchas de las veces no les alcanza el dinero para tener energía adentro de sus hogares, consideran que esto debería pagarlo la Alcaldía directamente y así se beneficiaria la población en general. Además "hay algunas cuadras donde las farolas del alumbrado público están dañadas ya sea por el uso o por la acción de las bandas armadas que las destruyen para poder hacer sus fechorías más tranquilamente y que no los puedan identificar y pueden durar así esas lámparas hasta tres meses sin prender y nos siguen cobrando igual".

Con los teléfonos, la gente que no tiene línea en su casa, prefiere el uso del teléfono celular por minutos para marcar, y uso del plan prepago para recibir llamadas, porque muchas de las veces nunca recargan una tarjeta para llamar. Los teléfono públicos gratuitos son contados en la zona y los pocos se ubican a largas distancia, sumado a ello las filas para llamar a veces son extensas, por lo que resulta incomodo. 
El problema de las basuras, es un poco complicado de manejar, ya que debido a las condiciones del terreno y a la poca accesibilidad, el carro recolector no puede llegar sino hasta las entradas de los sectores, pero si generan el cobro del servicio de saneamiento y recolección de basuras de manera normal; con éste panorama algunas personas prefieren tirarla a rodar escalas abajo sus basuras, hasta los límites con el Barrio 20 de Julio, generando problemas de todo tipo.

Una queja constante de la población son los altos costos de los SPD para el estrato 1, y manifiestan un alza indiscriminada en las facturas: "las cuentas han subido mucho, por ejemplo acá pagábamos de luz primero 30.000 pesos, luego que 45.000 pesos y ahora ya está llegando por 60.000 pesos"; $y$ otra queja frecuente es que a pesar que muchas familias cocinan con gas la cuenta de luz les llega muy alta y no se explican por qué.

Este fenómeno se puede explicar con la llamada "Equidad Tarifaria de Antioquía", que acude al concepto de la solidaridad, buscando con ello, que los habitantes de Medellín subsidiaran a los campesinos de Antioquia, es de recordar que ésta es una responsabilidad de la empresa y del gobierno. Y además dicha equidad no se dio sobre el tope más bajo sino sobre el más alto, ahora bien, si observamos que la cantidad de usuarios de la energía en el Área Metropolitana es de 3.500.000 habitantes a los que se le subieron las tarifas, mientas que solo le rebajaron a un 1.500 .000 personas que viven en el resto de Antioquia.

Frente al saneamiento hay una queja similar, pues antes se pagaba igual por agua $y$ alcantarillado y hoy está llegando el doble para alcantarillado. Además en la factura no se aclaran los componentes del costo de este servicio como se hace con el de la energía, cuando es una condición que pone la Superintendencia de SPD.

Lo que no se explica es porque a los habitantes del centro y norte de la ciudad sin tener planta de tratamiento de aguas residuales se les cobra una tarifa tan cara, además aún el mal servicio de alcantarillado, se factura la misma tarifa como si fuese de optima calidad.

Un problema permanente, para sus habitantes, es el famoso cobro, en las facturas, de las relacionadas como "Otras entidades", ya que nadie entiende cómo allí los costos se han venido incrementando y sin quien responda por ellos.

La mayoría de las familias del barrio se encuentran desconectadas, debido entre otras cosas a las altas tarifas de los servicios públicos. La gente considera que esto se puede deber a que en el tiempo de la guerra y cuando dominaban las milicias no se les permitían entrar a las EPM y por lo tanto no se les cobraba por estos servicios, dominaba la ilegalidad. Debido a ello, los habitantes comentan que estas altas tarifas obedecen a una especie de "afrenta" por parte de EPM, por los años que consumieron y no pagaron. 


\subsubsection{Los Desconectados}

Para el análisis de este Sub-capítulo tuvimos en cuenta dos recolecciones casos que se hicieron, la primera durante el 2007 en el marco de la Audiencia Popular de Juzgamiento a las Empresas Prestadoras de SPD en Antioquia y la segunda dentro de la Propuesta de Foro Social Medellín en el 2008. En la primera se lograron recolectar 26 casos y en la segunda 15. En cuanto a lo cuantitativo se retomaron los datos de la segunda recolección, ya que eran los más recientes y con un instrumento más pertinente y eficaz y fue planteado específicamente para esta investigación; pero frente a los datos cualitativos se tomo en cuenta las dos jornadas de recolección porque las realidades eran muy similares y realmente el panorama y la situación de desconexión no había cambiado mucho.

De una muestra significativa de 115 hogares encuestados durante los meses de septiembre y octubre de 2008 , se encontró que $12.3 \%$ de las familias está desconectada de algún servicio público domiciliarios, de ellos el $42.8 \%$ se encuentra sin agua, luz y teléfono; el $21.4 \%$ de luz y teléfono, el $14.2 \%$ del agua y la luz, el $14.2 \%$ de solo energía y el $7.1 \%$ de solo teléfono. De los hogares desconectados el $38.4 \%$ están cortados $^{28}$ y el $61.5 \%$ están suspendidos; y de los suspendidos $^{29}$ el $25 \%$ lleva entre 7 y 11 meses sin servicios, el $25 \%$ entre 1 y 3 años; y el $50 \%$ lleva más de 4 años desconectado.

Y el problema no acaba ahí, deteniéndonos a mirar las cifras, encontramos que otro $12.3 \%$ de la población ha financiado o refinanciado algún servicio público de los tres mencionados y otro $10.6 \%$ se ha acogido a la estrategia de energía prepago. Es decir que si sumamos estos valores con los de los desconectados, podemos afirmar que aproximadamente el $35.2 \%$ del total de la población está o ha estado en algún momento sin los servicios básicos para una vida digna.

Las familias que más sufren la desconexión son aquellos ubicados en los interiores de las casas, es decir en las partes más adentro de los callejones secundarios y con pocas posibilidades de acceso a los callejones principales del sector. Todas las viviendas están clasificadas en estrato 1 . De las viviendas desconectadas el $28.5 \%$ son ranchos en tablas y plástico, piso en tierra y techo de zinc; el $57.1 \%$ son casas en adobe pero muchas veces sin revocar; $y$ el $14.2 \%$ son construidas entre ladrillo y tablas.

Todos sus moradores de estas viviendas pertenecen al nivel 1 del Sisbén (lo que da cuenta de su condición de pobreza); están compuestas por un promedio de 6.2 habitantes por hogar, y de lo peor de todo es que de esta población el $48.8 \%$ son niños menores de edad, el $7.9 \%$ son adultos mayores, el $6.8 \%$ son enfermos físicos o mentales, un $5.6 \%$ son madres cabeza de familia y un $3.4 \%$ son discapacitados. O sea que es una población con un alto grado de vulnerabilidad, ya que estamos hablando que un $72.5 \%$ del total de las personas desconectadas de las Independencias II se encuentran en una situación de indefensión.

El 66.6 de los desconectados manifestó que la causa de su problema radica en la falta de dinero para pagar la cuenta de SPD, un 16.6 respondió que era debido al desempleo del jefe del 
hogar, un $8.3 \%$ a que la cuenta se subió debido a las altas tarifas y no les alcanzó para pagar y otro $8.3 \%$ porque los dueños o arrendatarios anteriores dejaron cuentas pendientes por cancelar.

Y relacionando un poco las causas con las fuentes de ingresos, nos damos cuenta que la situación socioeconómica de estas familias no es la más deseable. Lo primero que se nota es que a éstas personas no les alcanza para pagar la cuenta, pues lo poco que ganan es destinado a la alimentación y muchas veces ni siquiera les alcanza para eso, tienen que recurrir a la ayuda de algún vecino o hacer los famosos "recorridos" en busca de mercados por sectores como Laureles o las plazas de mercado, esperando que les regalen algo para comer.

Se encontró que un $50 \%$ de los hogares de los desconectados, solo una persona trabaja, pero con el agravante de que no son trabajos dignos, sino que pertenecen a la categoría de subempleados, es decir no laboran todo el tiempo, o solo lo hacen por días, o el trabajo no es lo suficientemente remunerado para la labor que se realiza. Mucha de esta población se dedica a las ventas ambulantes, el cuidado de niños, lavando ropa por días, en arreglos eléctricos y albañilería por días, entre otros oficios como celador o lavador de carros.

Para estas familias sus ingresos mensuales son aproximadamente $\$ 350.000$ y teniendo en cuenta que el promedio de personas por hogar es de 6, nos da la irrisoria suma de $\$ 58.000$ con la que tiene que sobrevivir cada integrante de la familia, es decir que cada persona sobrevive con menos de $\$ 2.000$ pesos diarios. Aquí la pregunta es żcreé usted, como ciudadano del común, qué con estos ingresos se pretenda que se pague la cuenta de SPD? Pues déjeme decirle que es imposible, y si fuera posible es inaudito que la gente de los sectores populares en vez de comer, engorde las ganancias de una empresa como EPM que obtiene más de 1,3 billones de ganancias en un solo año.

Y volviendo a las cifras, se halló un alto porcentaje de desconectados que no tienen ninguna clase de empleo, sino que viven del rebusque en la calle, allí encontramos a un $28.5 \%$ de la población sin SPD, cuyo promedio de ingresos mensuales oscila en \$115.000. Si los subempleados vivían en la pobreza, esta gente vive en la indigencia, sin lo mínimo para una vida digna. Y por último un $21.4 \%$ de los desconectados tiene un empleo medio decente del cual recibe un salario mínimo, es decir aproximadamente $\$ 550.000$ mensuales.

Respecto a la deuda que tienen con EPM, el 27.2\% de los entrevistados deben menos de un millón de pesos; el $36.3 \%$ entre 1 y 3 millones; el 18.2\% más de cuatro millones y $18.2 \%$ no sabe a cuanto asciende su deuda. A mucha de esta gente que no posee los ingresos económicos suficientes les queda muy difícil cancelar esta deuda, y se puede decir que es casi imposible, ya que si no pudieron pagar una factura a tiempo, mucho menos estas grandes cantidades de dinero y antes que llegar a una negociación con EPM para cancelar lo que deben prefieren alimentar a su familia. 
El 35.7\% ha intentado negociar con EPM a través de la financiación de su deuda, pero vuelven a ser desconectados nuevamente porque no tienen con qué pagarla, muchas de las familias han financiado hasta tres y cuatro veces su deuda, y cómo no son capaces de ponerse al día, ya las EPM les niega cualquier posibilidad de acceder a un nuevo plan de refinanciación. Otro $28.5 \%$ busca la salida de negociación a través de la energía prepago (ya sea que la tenga en su casa o tenga cita para adquirirla). Y por último un 35.7\% no ha intentado ninguna estrategia con EPM, se las arreglan por otros lados.

Y bueno, mucha gente se preguntará cómo acceden a estos servicios públicos, pues la respuesta está dada de la siguiente manera: un 33\% de la población toman el agua y la energía prestados de los vecinos, en un acto de solidaridad frente a los más necesitados y máxime cuando en la casa de al lado existen muchos niños o personas mayores, algunos lo hacen, para el caso del agua a través de baldes o mangueras y para el caso de la luz les pasan un cable para que se peguen. Un $25 \%$ optan ya sea por el prepago o el fraude para obtener luz y el agua se la pasan los vecinos. Otro $25 \%$ opta por el fraude y/o contrabando, y un último $16.6 \%$ toma el agua de fraude, pero se alumbra con velas y cocina con leña.

El total de las personas desconectadas coincide en afirmar que el agua y la energía son importantes para la vida y para su desarrollo personal como seres humanos; que sin agua nos moriríamos de sed y es necesario para la alimentación, que es un factor importante a la hora de tener una buena salud y un buen saneamiento tanto a nivel personal como de la vivienda, que es importante para bañarse y para lavar la ropa, además de considerar que sin agua no se puede hacer nada ya que sin agua no hay vida. Y otros aseveran que sin luz estamos muertos y viviendo como en la época de las cavernas y que sin energía no hay quien aguante prendiendo leña todos los días para poder cocinar. En resumidas cuentas como lo narra una desconectada: "sin agua y luz no se vive dignamente".

Los habitantes son consientes de que los SPD son derechos fundamentales, especialmente el agua (acueducto y alcantarillado), planteando "żsin agua quién vive?", considerándolo además muy necesario y que es un servicio que deben tener todas las viviendas. Respecto a la energía son un poco más flexibles, lo consideran importante y que tienen derecho como ciudadanos, pero bien se podría sobrevivir sin luz.

Al preguntársele a la gente que percepción tenían frente a la desconexión, las respuestas fueron muy variados pero en la misma línea y con el mismo sentido, con una sensación de insatisfacción y malestar. Algunos incluso llegaron a decir que se sentían humillados por no tener SPD y estar pidiendo ayuda a los vecinos constantemente. Otros manifestaron su inconformidad con el corte de los servicios planteando que no deberían quitarlos nunca y máxime si ese hogar viven niños. Estuvieron los que no entendían porque no se les perdonaban las deudas, si hasta aguantaban hambre. Y por último, especialmente los líderes comunitarios fueron más allá y llegaron a plantear que la desconexión era un crimen, porque el agua es muy importante para la vida, que el prepago era un engaño y que el Estado debería proteger el derecho a los SPD porque era su obligación para con los ciudadanos especialmente los más necesitados. 
Es muy evidente también, que no ven como responsables de la desconexión a los trabajadores de las EPM, sino a la empresa Desconectadora como tal: "la desconexión es una injusticia porque tenemos muchos niños, y ellos (EPM) no tienen compasión y solo dicen (los empleados) que están recibiendo ordenes". Muchos también consideran que las EPM deberían tener otras soluciones a la desconexión, que deberían cambiar la forma de quitar el agua y la luz, deberían llamar antes de hacerlo y dar alguna alternativa de pago. Piensan que a las EPM les hace falta solidaridad y un mejor método de financiación para poder conectarse legalmente.

La gran mayoría consideran muy alto el costo de los servicios, además de que no entienden porque les llega tan alta la factura, si es estrato 1 y no tienen muchos electrodomésticos. Muchos de sus líderes piensan que debería buscarse una solución más de fondo al problema y que "los servicios deberían ser más baratos para poder pagarlos. No deberían cobrar tan caro y perdonar la deuda".

Muchas de las personas se inclinan por creer que la desconexión es una injusticia, aquí algunos de sus comentarios: "Considero injusta la desconexión, no es justo que unos tengan los SPD y otros no, solamente porque tienen un poquito más de dinero". "No me parece justo la desconexión, la pobreza es mucha y a veces toca priorizar los asuntos". "EPM y el Gobierno No deberían ser tan injustos con la gente en los barrios populares, porque por ejemplo acá en la comuna la mayoría somos madres cabeza de familia, sin recursos suficientes y por lo tanto las tarifas deberían ser más bajas". "La desconexión es algo triste, teniendo en cuenta que somos gente muy pobre y lo cortan a uno así como así", "Sin la luz y el agua no somos nadie" son algunas de las versiones que dan cuenta de esta crisis humanitaria y de emergencia social.

Entre las principales causales de la desconexión en el barrio se encuentra: la falta de capacidad de pago de la población, ya sea porque el jefe del hogar se encuentra desempleado, presenta inestabilidad laboral o sus ingresos son insuficientes, agravándose la situación cuando es una madre cabeza de familia la que no tiene empleo. "Fui desconectada porque me quede sin empleo, quede embarazada y me tocó parar de trabajar".

También figuran aunque en menor rango, pero no menos importantes: la acumulación de cuentas que luego se hacen impagables y en las casas arrendadas que los antiguos inquilinos no pagaran los SPD. "Una de las razones para quedar desconectada fue que mi esposo se quedo sin empleo, nos cogió ventaja las cuentas y ya no pudimos pagar más, además yo me enferme y no pude trabajar más". De igual forma encontramos varios casos en el que la gente que refinancia su deuda actual con las EPM y luego ya no pueden pagar las cuotas tan altas: "La factura me llegaba regularmente por 12,000 de luz, 14,000 de teléfono y 18,000 de agua, pero con la refinanciación me estaba llegando por 250,000. Actualmente adeudo a las EPM $1,400.000$ pesos $^{\prime \prime 30}$.

Y por último por razones del conflicto armado en la comuna, por ejemplo cuando matan y/o desaparecen a uno de los miembros que aportan ingresos al hogar o que cooperaban con el pago de la cuenta de los servicios públicos. O la más lamentable es que cuando la época dura 
de la guerra que se dio en la comuna, a la gente le tocó salir desplazada para preservar sus vidas, y ahora que retornaron a sus viviendas, uno la encontraron destrozada y dos les tocó pagar las deudas de los SPD y del predial de los bandidos que los desplazaron. Ante esta situación a la Alcaldía y las EPM no parece importarles nada a pesar de las múltiples denuncias que se han hecho, lo único que plantean es que la gente refinancie su deuda, cuando lo que debería aplicarse es una condonación de las mismas.

\subsection{3.. El fraude como una alternativa de supervivencia.}

Ante la desconexión, mucha de la gente busca como la alternativa más rápida y eficaz, aunque no legal, el contrabando y pirateo de la energía y del agua; otros deciden recurrir a la caridad de sus vecinos, algunos optan por recoger leña para cocinar y alumbrarse con velas, y otros con pagarle a un vecino para que comparta sus servicios y a la hora del pago dividirse la cuenta. "Actualmente tengo el servicio de energía y agua por medio del fraude, ya que mi hermana nos suministra el agua y nos pasa un cable de luz y nosotros le ayudamos a pagar la cuenta, pero ya hemos tenido varios problemas, ya que si por ejemplo prendemos dos fogones a la vez, se dispara el breaker" ${ }^{\prime \prime 1}$. No ha podido reconectarse legalmente por falta de dinero, pues no tiene empleo actualmente "si consigo para la comida, no tengo pagar los SPD".

Una historia parecida es la de doña Olga, que desde hace 3 meses está colgada de la luz, y el agua se la pasa a una vecina que le trae la manguera. "Con el fraude estoy conectada de la luz para poder hacer la comida a mis hijos que tengo estudiando, pues como los voy a mandar a la escuela sin ningún tipo de alimento y unas condiciones mínimas de aseo, como lo es el baño diario, por eso en estos momentos el agua me la pasa una vecina de al lado por medio de una manguera. El contador de agua se me lo llevaron (en este momento está funcionado de manera directa el servicio) y el de la luz me lo dejaron, pero en la actualidad estamos pegados con un cable y cada vez que van los de las EPM me lo quitan y nosotros volvemos y lo conectamos ${ }^{\prime \prime 2}$, por esta razón tienen cuentas pendientes con la empresa. Actualmente tiene una multa por fraude, pero no sabe cuánto adeuda, pide a las EPM que no le cobren ésta, ya que ella recurrió a la ilegalidad en un momento de desespero y angustia y además por necesidad, porque ¿̇cómo podrían vivir nueve niños y una anciana si no tienen agua y energía por lo menos?

A las personas que las EPM les pillan el contrabando, le imponen una multa por $\$ 200,000$ la primera pez, si reinciden $\$ 400.000$, ya luego aumenta a $\$ 800.000$ y así sucesivamente. Además se les llevan el cable de luz y les dañan el tubo madre del agua. Con estas deudas, familias que nunca tuvieron con qué pagar la cuenta mensual mucho menos van a poder pagar todo ese dinero que deben, por lo tanto nunca podrán acceder a la legalidad en el servicio y por ello encontramos familias hasta con 6 años de desconectados y con multas hasta de 5 millones.

Muchos de los desconectados aunque saben que esto se constituye en un delito penal, lo hacen como única forma que se tiene para subsistir. No han podido conectarse legalmente ya que están adeudando mucho dinero a la empresa, y no tienen los suficientes fondos económicos 
para pagarlos. Es así como estas familias nunca retornarán a la legalidad, a menos de que se les ofrezca una condonación a sus deudas, pues ni refinanciando lo lograrán. Si pagan no tienen para la comida y si les cortan el contrabando se mueren de hambre porque necesitan la luz para la cocción de sus alimentos.

Para el caso del agua deciden abrir la llave de paso, y cuando la llave está dañada, la dejan de forma directa. "Yo he utilizado el fraude para acceder al agua, recurrí a destapar el contador, sobre todo por los niños y por salubridad básica en mi familia". Aunque, "como pusieron un tornillo al tubo madre del agua, me costó 8 días para abrir de nuevo, pero otra vez recibo el agua aunque sea ilegalmente".

"Sí utilizi el fraude, tengo una cuerda pegada al poste. A veces me la quitan los de las EPM, pero yo solo la utilizo para alumbrar la casa y cocinar, por lo tanto la considero un derecho. No he podido conectarme legalmente ya que mi esposo no tiene empleo fijo, y estamos refinanciando la casa" ${ }^{\prime \prime 3}$.

Pero también se pudieron constatar casos en donde las viviendas no poseen fraude, un vecino les da la luz y parten la cuenta de servicios. Y el agua se la regalan los vecinos, ya sea través de baldes o pasándoles una manguera, pero los vecinos no tienen el mismo genio siempre y a veces se cansan. Otros deciden cocinar con gas, con leña o con petróleo y alumbrarse con velas. "Me tocaba cocinar con leña dentro de la casa, a pesar de que a los vecinos les molestara tanto humo. Además se me enfermó la bebé de bronconeumia".

Pero esta situación no es sólo en el barrio, en la ciudad de Medellín, de marzo a diciembre de 2007 se contabilizaron un total de 21.787 reconexiones fraudulentas, en el servicio de agua. Para el caso de la energía, durante el año 2007 se han descubierto 8.577 reconexiones fraudulentas, de las cuales 2.239 ya han cumplido el debido proceso con el cliente y están facturadas y 6.338 están en trámite en el equipo de Liquidación y Notificación de sanciones de las $\mathrm{EPM}^{34}$. De estos fraudes el $85 \%$ son cometidos en los estratos 1 y 2 , por personas que generalmente no trabajan o están subempleadas.

\subsubsection{La Financiación de las deudas}

Respecto a la refinanciación, en el barrio existe una gran aversión hacia ella, la consideran perversa y que realmente no soluciona el problema, ya que muchos de ellos no tienen un trabajo constante como para estar pagando el consumo actual más las deudas anteriores. Estos son algunos de los casos: "He refinanciado la deuda en tres oportunidades, pero siempre es lo mismo, no me alcanzan los ingresos para cubrir mi compromiso y vuelven y me desconectan. Si en este momento me condonaran la deuda, yo podría seguir pagando el consumo por mes". "Tengo 2 financiaciones. Desde diciembre estamos sin luz. No pudimos con la última parte de la refinanciación y perdimos toda la plata invertida". Otro caso son familias que la financiación la hicieron los dueños anteriores de las viviendas y les toca pagar lo que ellos quedaron debiendo 
además con las cuotas que ellos fijaron para pagar.

Uno de los impedimentos además de la falta de dinero para financiar la deuda, es que las EPM pedían una cuota inicial, que en algunos casos llegaba a ser de $\$ 200.000$, cifra relativamente alta, entonces como no llevaban la totalidad de la plata no han podido hacerlo. Además EPM les pide impuesto predial y escrituras de la casa, pero muchas de las viviendas aún no tienen los papeles. Además de la carta de desplazada a los que se encuentran es esta situación.

En Medellín, algunos usuarios desconectados, han decidido refinanciar sus deudas, a través de estos planes de financiación, está modalidad ha sido acogida por 274.623 usuarios, durante los últimos tres años, distribuidos de la siguiente manera: el año 2005: 122.027, en el 2006: 90.892 y en el 2007: 61.704 usuarios. Lo que nos demuestra que es una estrategia que no soluciona el problema de los desconectados, ya que si observamos la cantidad de usuarios que se acoge a estos planes y la reducción del número de desconectados, vemos que ha sido ineficiente.

\subsubsection{El Drama Humano de la Desconexión:}

Cuando un hogar es desconectado de los SPD, sufre de graves problemas relacionados con la convivencia dentro de los integrantes de la familia. Los niños aunque no son muy conscientes de la realidad por la que atraviesan son los que más les hace falta por ejemplo la luz, tanto para hacer sus tareas durante la noche, o para poder ver televisión, además de que muchos les temen a la oscuridad. Además de la pena que les da por no tener luz en su casa, mientras sus amiguitos vecinos si la poseen. Los menores de edad se quejan mucho ante los padres porque no prenden los bombillos en la casa. Y ante situación de insistencia de los menores, los padres se desesperan sin saber qué hacer, cómo solucionar el problema, optan en algunas de las veces por regañar a sus hijos por las insistencias o recurren al fraude como única alternativa de sobrevivencia. En muchas de las visitas pudimos observar como algunas familias al no tener luz no habían podido comer (pues tienen fogón de energía), y los niños llorando por el hambre, ante esta situación muchos deciden pedir ayuda a sus vecinos por los primeros días, pero luego éstos se cansan y les toca recurrir a cocinar con leña, o esperar a recoger algo de dinero para que los conecten de contrabando y esperar a que vengan lo de las EPM a desconectarlos de nuevo y ponerles una multa por fraude.

Los padres de familia se desesperan al saber que no tienen con qué pagar la cuenta, algunos tienen graves problemas de estrés y situaciones de paranoia, porque tienen que estar muy pendientes del carro y los técnicos de las EPM, temiendo ser descubiertos y tener que pagar las multas respectivas.

Otra es la cosa de aquellas familias que a pesar de no ser desconectadas tienen conflictos intrafamiliares, generados por el uso "excesivo" de los SPD, por parte de los habitantes del 
hogar. Es común en las familias de todos los estratos, especialmente los populares, altercados cuando llega la factura de los servicios, debido entre otras cosas a las altas tarifas. Las familias se estresan por no tener con qué pagar, debiendo reducir los gastos para otros rubros como la alimentación, el vestido y la recreación, para evitar ser desconectados.

\subsection{6.. La Problemática no es solo en el Barrio, es en toda la Comuna.}

Si bien, en la cobertura de servicios públicos, la comuna 13 presenta un 100\% en energía y un $87 \%$ en acueducto, el problema central se presenta con respecto a la capacidad de pago que tienen los usuarios, debido a las políticas de desmonte se subsidios para los estratos 1, 2 y 3 . Este conflicto se ha manifestado en la resistencia al pago de las cuentas de servicios y a la irregularidad en la prestación de los servicios (problemas de conexión, reconexión, incremento del contrabando, uso de pilas públicas, etc.).

A este respecto el plan de desarrollo de la comuna 13 comenta: "respecto a los Servicios Públicos y según dato de EPM, el 100\% de las viviendas de la comuna, cuenta con servicios de energía eléctrica, el $73.4 \%$ del total cuentan con teléfono privado; conectadas a la red de acueducto $96 \%$. En cobertura de alcantarillado y de acueducto, el estudio aparece sin información al respecto. Estos datos tienden a ser modificados sustancialmente, por el incremento de viviendas informales en los últimos 5 años, que no cuentan con instalaciones legalizadas, y menos en alcantarillado.

Estos datos a simple vista son alentadores, pero consideramos que más importante que tener las acometidas en las residencias, es poder garantizar el uso y disfrute de estos servicios, lo cual no depende directamente de la voluntad de los habitantes, sino de las condiciones económicas de cada familia, lo que sabemos que no es del todo segura. Desafortunadamente no se cuentan con estadísticas discriminadas de desconectados en la Comuna 13, pero asumimos que al igual que la Comuna representa cerca del $6 \%$ de la población de Medellín, de la misma manera debemos poseer de entre los más de 60.000 desconectados actuales de la ciudad, mas de 3.600 familias en iguales condiciones" ${ }^{\prime 35}$.

Por otro lado y en contradicción con las EPM, encontramos datos según el Departamento Administrativo de Planeación de Medellín, Subdirección de Metroinformación.2008 ${ }^{36}$, que manejan esta otra información sobre la comuna 13: 


\begin{tabular}{|l|l|c|}
\hline \multirow{5}{*}{ SANEAMIENTO } & Acucto & 657 \\
\hline \multirow{4}{*}{ BASICO } & Número de viviendas sin acueducto & $2,0 \%$ \\
\hline & \% de viviendas sin conexión al acueducto Municipal \\
\cline { 2 - 3 } & Aguas residuales & 229 \\
\cline { 2 - 3 } & Número de viviendas sin servicio de sanitario & 207 \\
\cline { 2 - 3 } & Número de viviendas sin conexión a alcantarillado & 949 \\
\cline { 2 - 3 } & $\%$ de viviendas sin conexión al alcantarillado Municipal & $4,3 \%$ \\
\cline { 2 - 3 } & Desechos sólidos & \\
\cline { 2 - 3 } & Número de vivienda que no tienen recolección de basuras & 649 \\
\cline { 2 - 3 } & $\%$ de viviendas que no tienen recolección & $2,0 \%$ \\
\hline
\end{tabular}

Aquí podemos observar como un gran porcentaje de viviendas se encuentra sin el derecho al agua potable (acueducto, alcantarillado y saneamiento), por problemas relacionados con el acceso. Es decir que aproximadamente 2.826 personas están sin acueducto y además no se les recoge sus basuras y más de 6.000 personas no tienen servicio de alcantarillado, presentándose un grave problema social y de salubridad pública. Por eso insisto en que este fenómeno de la desconexión hoy en Medellín, debe declarársele como una EMERGENCIA SOCIAL.

En la comuna se recogieron un total de 35 casos de familias desconectadas, muestra que nos da pistas sobre lo que está sucediendo en este sector del occidente de la ciudad. Allí su población ha tenido problemas con los SPD desde su fundación, ya que muchos de los barrios fueron de invasión, por lo tanto ni el gobierno, ni las EPM les prestaban el servicio, fue la misma comunidad que a través de convites y cartas ante la administración lograron poco a poco tener acceso a los SPD. Y ahora el principal problema que se presenta es que muchas familias, tienen las redes, pero no tienen con qué pagar el servicio, pues recordemos que allí se asienta la mayor proporción de familias en estrato 1 de la ciudad (67.800 personas), entonces no tienen recursos para cancelar sus cuentas a tiempo, engrosando el número de desconectados.

Muchas de las familias llevan años desconectados, aunque existen otras que apenas están empezando a aparecer en las cifras de las EPM. Las causas para encontrarse en esta situación, son muy variadas, pero lo común es que la gente no consigue como pagar, y no es que no quieran, sino que realmente no tienen el dinero. Una de las variables es que la cuenta empieza a subir y ya la gente no consigue pagar y se van atrasando hasta que son desconectados: "Estoy desconectada desde hace 4 meses del servicio de energía y un mes del servicio de agua. Una de la razones para ello fue que me estaba viniendo mucho la cuenta y una hija que era la que colaboraba en la casa ya no lo hace porque ya tiene sus obligaciones. La factura antes me llegaba por 55,000 aproximadamente, pero después me estaba llegando por 60,000 o 70,000 pesos. Actualmente debo a las EPM 1.700.000, pero no tengo de donde ${ }^{\prime 37}$.

Otra familia desconoce desde cuando fue desconectada, porque apenas compraron la casa y no tenían los SPD al día. Los inquilinos anteriores se atrasaban en las cuentas y no pagaban. 
No saben por cuánto le llegaba la factura, creen que aproximadamente debe actualmente 4,000.000 millones de pesos. Esta es su percepción frente a la desconexión: "Que son muy descarados (EPM) porque así les chillen lo cortan a uno, pero los trabajadores no tienen la culpa, es de la EPM". Aunque ella reconoce las deudas, considera que la empresa no tiene conciencia de la situación de la gente y no aceptan que se pague por cuotas asequibles a ellos. Ella es una madre cabeza de familia que no tiene empleo y el único hijo que le colaboraba en el hogar se murió. Historias como estas son la cotidianeidad en la comuna.

Otro caso impactante fue el de una señora ${ }^{38}$ que fue desconectada debido al desplazamiento forzado, ya que fue sacada de la comuna, se fue para Santa Elena y cuando volvió a su casa ya no tenía los SPD. Actualmente debe a las EPM 1,482.000 pesos (deuda de los antiguos inquilinos, los que la desplazaron, o sea los paramilitares). Esto demuestra como la guerra también ha afectado la población civil que nada tiene que ver en el conflicto, pero la que sufre las más crueles consecuencias de ella. Esta señora, primero sufre al salir de su vivienda y luego llega a encontrarse debiéndole dinero a una empresa por algo que ella no consumió, ¿parecería justo que ella pagará la cuenta de los SPD de estos bandidos? Historias como estas aunque dolorosas resultan bastante evidentes.

"Desde hace 5 años mi familia está sin los servicios de agua, luz y teléfono. Hace 2 años que no me llega la cuenta. Se me llevaron el contador del agua y cortaron el cable de la luz. Una de las causales de la desconexión, fue cuando mataron a mi marido, ya que mi esposo era una fuente importante de ingresos para toda la familia", ya que como lo manifestó doña Rosa: "el mercaba y yo pagaba los servicios", pero ahora deciden comer y por lo tanto les fueron cortados los servicios. "No podía pagar las cuentas porque los ingresos son insuficientes, en el momento de desconexión estaba desempleada". Pagaba mensualmente \$100.000 a \$112.000. A principios de 2006, la deuda era $\$ 1.100 .000^{39}$.

Este es otro ejemplo vivo de la situación por la que atraviesan estas familias: "Desde hace 8 años me encuentro desconectada de todos los servicios. Debido a que me he quedado sin trabajo, me alcancé en el pago de las cuentas que me llegaban por el valor de $\$ 70.000$ u $\$ 80.000$, hoy en día estoy adeudando $\$ 4.000 .000$ de pesos ${ }^{\prime \prime 0}$. Ella ha hecho cuatro refinanciaciones. Al no tener cómo pagar se conectó del poste de energía, pero llegaron los funcionarios de las EPM, y le cortaron el alambre, luego se pego de la casa de la mamá para obtener energía. Cuando le cortaron la energía del poste, los de EPM se le llevaron el alambre y le cobraron una multa. Esta situación la hace sentirse perjudicada al tener una deuda tan alta, además piensa que si paga la deuda no tiene con qué comer, priorizando por esto lo último. Como se pudo observar muchas de las historias son de madres cabeza de familia, ya que estos hogares no poseen padre, ya sea por abandono o por muerte.

Don Carlos, "Lleva 11 años desconectado de todos los servicios, pues estuvo dos años sin empleo lo que hizo que le tomara ventaja la deuda. Las facturas le llegaban por \$50.000, hoy por hoy desconoce a cuánto asciende su deuda. Alguna vez intentó refinanciar pero le solicitaron llevar $\$ 200.000$, los cuales no tenía. Se reconectó con un alambre que le quitan 
a cada instante, el agua la pudo poner de nuevo, pero de contrabando y actualmente están cocinando con gas" ${ }^{\prime \prime 1}$.

\subsubsection{Conflictos generados a partir de la Desconexión}

En esta situación, también hay que mostrar lo que hay detrás de muchos desconectados; es decir los riesgos, problemas y conflictos derivados de la desconexión de los servicios básicos a la población sin recursos económicos.

Aquí presentamos como alrededor de los SPD se pueden configurar relaciones de la población civil, con los grupos armados y estos con la Alcaldía y las empresas prestadoras de SPD, por ejemplo tal como lo relata el IPC: "desde el año 2000, se encontraba en expansión la estrategia de urbanización del conflicto armado para llevar la guerra a las ciudades, y la comuna 13 fue un escenario propicio para su desarrollo, ya que existían algunas condiciones sociales de protesta y de rechazo a las políticas de regularización en donde el Estado brindó escolta a los funcionarios de la EPM, encargados de aplicar las impopulares medidas de corte de servicios públicos, dándose inicialmente una protesta ciudadana que encontró eco en la "solidaridad" de los grupos armados de la zona (las milicias guerrilleras) que rechazaron por la vía armada cualquier acercamiento de los funcionarios para la ejecución de las medidas de legalización, evidenciándose así, la presencia de estos grupos en la vida social y política de la ciudad (...) en este caso, no hubo una política de concertación y negociación con las comunidades para llegar a un acuerdo sobre cómo avanzar en la superación de un problema estructural que aún se mantiene" ${ }^{\prime \prime 2}$.

Otro de los conflictos que se ha presentado con los desconectados es por el prestador del servicio; en el caso del asentamiento ilegal en la parte Alta de "El Socorro", sector conocido como Loma Oriental, Altos de la Virgen o Loma Verde, en la comuna 13, la gente debe pagar por conectarse fraudulentamente a los SPD. En este barrio se ubican 750 familias desplazadas por la violencia, que comenzaron a llegar desde el año 1998. Allí no poseen el servicio de alcantarillado, por lo tanto sus habitantes arrojan sus aguas negras a la quebrada.

La conexión ilegal está a cargo por desmovilizados de las AUC o grupos paramilitares, que tienen el control del barrio en sus manos. "Ese control se estaría haciendo evidente en el manejo de las conexiones ilegales de agua y luz que posee cada una de las viviendas del sector y por las que, dicen algunos vecinos, se pagan mil pesos semanales. Las denuncias al parecer no son nuevas... el año pasado, habitantes de la comuna 13 denunciaron que algunos desmovilizados cobran por permitir que los residentes de la zona se conecten fraudulentamente a los servicios públicos" ${ }^{\prime 3}$. "Los habitantes denunciaron... que si no pagan las cuotas, son obligados a salir del sector y señalaron que algunas personas no han podido volver a sus ranchos" ${ }^{14}$.

Otro de los conflictos y problemas es frente a las deudas de servicios públicos e impuesto predial de las viviendas despojadas por los grupos paramilitares que dominan la ciudad, especialmente 
los sectores populares. La personería de Medellín en su informe de derechos humanos de 2007 se pronuncio de la siguiente manera: "en lo que respecta a las deudas que las víctimas tenían por conceptos de servicios públicos domiciliarios e impuesto predial, las 85 familias respondieron que todas tienen deudas pendientes y que las mismas, corresponden al tiempo durante el cual han estado despojadas de sus viviendas. Sumadas las deudas de estas familias por ambos conceptos, el monto asciende a más de \$143.000.000, en algunos casos superan el valor comercial de las viviendas o lo que quedó de ellas. Además indicaron que para sanearlas, debieron endeudarse con uno de sus acreedores como EPM, o terceros, pagando a estos últimos altas tasas de interés. Importa indicar, cómo pese a que algunas de las víctimas en reiteradas ocasiones solicitaron a EPM después del desalojo, la suspensión del suministro de los servicios públicos domiciliarios, esta entidad siempre negó tal petición argumentando que solo podría cumplirse, cuando se configurara una mora en el pago" ${ }^{45}$.

\subsection{8. ¿Qué queremos como comunidad de las independencias?:}

Vivienda: Se necesitan muros de rehabilitación. Que Planeación Municipal les de las facultades para hacer los lineamientos reglamentarios para hacer el sistema de rehabilitación, presentando alternativas inmediatas.

- Que el barrio no se declare zona de alto riesgo, sino zona de alto costo.

- Se necesitan más subsidios para mejoramientos de vivienda, para que sea digna (baños y cocinas especialmente, además de techos y andenes de las viviendas) y son importantes para una buena sanidad de la población.

- Amueblamiento urbano y legalización de predios.

- Arborización de la zona.

Servicios Públicos Domiciliarios: - Reconexión inmediata de las familias desconectadas, con la aplicación de una "política de perdón y olvido" para sus deudas. Que no tengan que refinanciar, sino que les perdona.

- Aplicación de la propuesta del mínimo vital para el servicio del agua potable (acueducto y alcantarillado) de $20 \mathrm{mt}$. Cúbicos y $130 \mathrm{kw} / \mathrm{h}$ para todos los hogares del barrio.

- Que no se siga desconectando más a la gente, que antes de hacerlo se mire su situación socioeconómica.

- Rebaja sustancial a las tarifas de SPD, ya que todos somos estrato 1, por ejemplo de saneamiento básico y energía eléctrica rechazando su alza indiscriminada. 
- Hacer un estudio de sumideros donde llegan las aguas lluvias y las negras, ya que especialmente en la noche en el barrio salen malos olores de las alcantarillas. Hacer un proyecto de alcantarillado y su remodelación completa (que separe los dos tipos de agua), para así contribuir con el saneamiento del barrio, de las cuencas cercanas y del río Medellín.

- Que se redistribuyan las ganancias que EPM otorga al Municipio de Medellín, que sean utilizadas para atender la problemática de la desconexión, y sean para la inversión social, más no para infraestructura para el embellecimiento de la ciudad.

- Que el alumbrado público lo pague el gobierno central, no la gente.

- La refinanciación y la política de energía pre-pago no solucionan el problema.

- Apoyamos a los demás desconectados de la ciudad de Medellín (aproximadamente 200.000 personas). Tanto a los que no tienen con qué pagar, como a los que nunca han tenido agua potable ni alcantarillado.

Empleo: - A sabiendas de que una de las causas de la desconexión son la falta de empleo y de recursos económicos, pedimos a la administración municipal políticas de empleo estable para los jóvenes, adultos y la tercera edad.

- Capacitación para el empleo en los jóvenes (tanto hombres como mujeres), para cualificarlos técnicamente para la ocupación de cargos.

Salud: - Realización de brigadas de salud para toda la población, especialmente la más vulnerable: tanto salud física, como oral y psicológica.

- Que las citas del sistema de salud se hagan más rápido: de un día a otro, ya que actualmente se demoran mucho (hasta 10 días).

- Que tengamos acceso a droga de buena calidad, no droga de "segunda" (genéricos).

Educación: - Un subsidio de transporte para los niños, niñas y adolescentes para ir a sus lugares de estudio, ya que debido a las limitaciones de territorios impuestas por los actores armados corren riego si se van a pie.

- Ampliar la cobertura del programa para la primera infancia "Buen Comienzo", reconociendo su ejecución a los líderes de la zona. 
- Que el SENA haga mayor presencia en la zona, capacitando a la población.

- Cursos de pre-universitarios para los bachilleres para que tengan más posibilidades de acceder a la educación superior pública.

- Una biblioteca más cercana, así sea un poco más pequeña que las nuevas.

- Una sala de cómputo con internet que sea gratis para los niños y adolescentes estudiantes, que sirvan para reforzar sus actividades escolares.

Niñez: - Implementación del programa de la Alcaldía: "Desayunos Infantiles".

- Garantizar la seguridad alimentaria a todos los estudiantes niños, durante los días que no son escolares, es decir los fines de semana.

- Ampliar la cobertura de los refrigerios y almuerzos de los restaurantes escolares, para todos los estudiantes.

- Lugares de encuentro para los niños, como la construcción y adecuación de parques infantiles.

- Jornadas Lúdico-Recreativas para los menores (cine, teatro, música, deportes, aeróbicos...)

- Incentivar programas educativos para desaprender la violencia y aprender la cultura de paz, para evitar que estos niños en un futuro ingresen a grupos armados. Además de implementar esta cátedra en todas los planteles públicos de la zona.

Tercera Edad: - Ampliar la cobertura y el presupuesto para los subsidios a la tercera edad.

- Implementar y ampliar la cobertura de complemento alimentario al adulto mayor "Juan Luis Londoño de la Cuesta".

- Quitar la restricción que plantea que si al adulto mayor le dan subsidios no recibe servicio de restaurante y viceversa.

- Jornadas lúdico-recreativas.

Otros: -Que las Madres Cabeza de Familia, puedan laborar desde sus hogares, para que estén más pendientes de los hijos. 
- A los desplazados, una mejor atención y que les acaben de cubrir sus necesidades básicas.

- Que a las personas que tengan que salir reubicados de la zona, el gobierno les garantice sus derechos, brindándole oportunidades favorables para una nueva adquisición.

- Una casa comunitaria que permita la integración y la articulación de la comunidad, donde se puedan dictar las charlas, capacitar a la población, presentar videos y hacer talleres para los niños y adultos.

- Apoyo a la cultura popular, a través de la enseñanza del baile, la danza, el teatro y la música (conformación de una chirimía).

- Una mesa de negociación con las EPM y la Alcaldía Municipal, para debatir el futuro de las Independencias, sus principales problemáticas sociales, entre ellas la desconexión y cómo vamos a hacer para el mejoramiento de la calidad de vida de sus habitantes.

En fin, lo que queremos es la paz con justicia social, igualdad y fraternidad.

\subsubsection{Recomendaciones para próximos investigaciones sobre la problemática.}

Es muy importante que se sistematicen todas estas experiencias y los procesos que se resisten en medio de condiciones indignas de vida, de la sociedad civil en la ciudad de Medellín, que se acompañen desde el trabajo popular, que se reflexione sobre nuestras prácticas cotidianas, para así aprender a conocer cómo trabajamos, que falencias tenemos y cuáles son nuestras fortalezas.

Se hace un llamado especial y fraterno a todos los estudiosos del tema, a que nos pensemos cómo desde la academia, a través de la investigación social, también se pueden generar procesos organizativos y de cambio y movilización social. Que la academia sirva a los intereses no del capital, sino de quienes más lo necesitan, los marginados y excluidos de nuestra sociedad, pues ellos también son personas y merecen ser escuchadas. Por ello nuestro papel es mostrarle a la ciudad y al país entero, lo que los gobiernos ocultan en nuestras comunas populares, que no solamente son problemas relacionados con los SPD, sino también de hambre, miseria, falta de educación, vivienda digna y salud, y todos los problemas que ha generado la violencia en estos territorios.

Es primordial que se construyan muchos registros fotográficos y/o de video de todas las actividades que se realicen, de las entrevistas, de los lugares, de los talleres, de las visitas domiciliarias y de las pruebas que se recojan.

Hacen falta muchas más investigaciones no sólo de diagnóstico sino de intervención social con las comunidades sin SPD, de carácter práctico y para formular soluciones reales a sus problemas. Se necesitan muchos abogados para sustenten la parte jurídica dentro de la lucha social y líderes comunitarios que crean que "otra ciudad es posible sin miseria ni exclusión". 


\section{Referencia Bibliográfica:}

Salgado, Carlos. "En la comuna 13 el agua genera disputa". El Colombiano, 9 de octubre de 2006. Pág. $10^{a}$.

Plan de Desarrollo Comuna 13. (2001) "Sembrando para el futuro y desarrollo integral"

Instituto Popular de Capacitacion. Informe sobre el estado actual de los derechos humanos en la comuna 13 de la ciudad de Medellín 2005. En: comuna 13 2005.rtf.

Periódico "De la Urbe". Año 4, N 15. Medellín, agosto de 2002. pág. 12.

"Camellan como hormigas". Periódico El Mundo, 3 de setiembre de 1992. Pág. 6.

La comuna 13, entre los sueños y la realidad. 17 de junio de 2004. En: www.ipc.org

¿Esto es la Independencia? Un barrio que le falta mucho pero que se ve el avance. Periódico El Colombiano, 9 de octubre de 1999, pág. 1B.

Ramirez, Elkin. (2008) Memoria histórica de la comuna 13 de Medellín. 26 de febrero de 2008. En: Revista EUPHORION Nº 3, julio-diciembre de 2008. Pag: 36-39.

${ }^{2}$ Datos tomados del Departamento Administrativo de Planeación de Medellín. Subdirección de Metroinformación. 2008.

${ }^{3}$ Se consideran en esta situación los hogares residentes en las viviendas con más de tres personas por cuarto (excluyendo cocina, baño y garaje).

${ }^{4}$ Hogares que habitan en viviendas en ranchos o viviendas de desechos, sin paredes o con paredes exteriores de tela, desechos, material semipermanente o perecedero (bahareque, guadua, caña o madera) o con piso de tierra.

${ }^{5}$ Proyectos para el fortalecimiento de la convivencia. En: http://www.fundacionapoye.org/php/ consulta 25 noviembre 2008.

${ }^{6}$ Datos según Síntesis del diagnóstico participativo de la comuna 13, elaborado por el CCDI en el año 2001.

7Plan de Desarrollo Comuna 13. "SEMBRANDO PARA EL FUTURO Y DESARROLLO INTEGRAL" 
${ }^{8}$ Datos tomados del Departamento Administrativo de Planeación de Medellín. Subdirección de Metroinformación. 2008.

${ }^{9}$ Naranjo, Gloria. Medellín en zonas. p. 194.Citado por FUNDACIÓN SOCIAL. Conoce tu zona.

${ }^{10}$ Fundación Social. Conoce tu zona. Piensa en el futuro. Autodiagnóstico de organización y participación. Medellín, 1996, p.3.

${ }^{11}$ Instituto Popular De Capacitacion. Informe sobre el estado actual de los derechos humanos en la comuna 13 de la ciudad de Medellín 2005. En:

www.kolko.de/downloads/IPC_comuna13_2005.rtf.

${ }^{12}$ Periódico "De la Urbe". Año 4, N 15. Medellín, agosto de 2002. pág. 12.

${ }^{13}$ Plan de Desarrollo Comuna 13. "SEMBRANDO PARA EL FUTURO Y DESARROLLO INTEGRAL"

'Luna, María Teresa. Gonzalez, Diana María. Desarrollo integral local. Evaluación del impacto del modelo DIL en la comuna 13 de Medellín. Fundación Social, Bogotá, 2004, pág. 17

lbíd. Pág. 17

${ }^{14} E n:$ "Camellan como hormigas". Periódico El Mundo, 3 de setiembre de 1992. Pág. 6.

${ }^{15}$ La comuna 13, entre los sueños y la realidad. 17 de junio de 2004. En: www.ipc.org

${ }^{16}$ En: "Camellan como hormigas". Periódico El Mundo, 3 de setiembre de 1992. Pág. 6.

${ }^{17} \mathrm{En}:$ "¿Esto es la Independencia? Un barrio que le falta mucho pero que se ve el avance. Periódico El Colombiano, 9 de octubre de 1999, pág. 1B.

${ }^{18}$ En: "Camellan como hormigas". Op. Cit.

${ }^{19}$ Testimonio de Gabriel Orrego, líder del barrio Las Independencias. 11 de octubre de 2008.

${ }^{20}$ lbidem.

${ }^{21}$ En: "Camellan como hormigas". Periódico El Mundo, 3 de setiembre de 1992. Pág. 6.

${ }^{22}$ Testimonio de Gabriel Orrego, líder del barrio Las Independencias. 11 de octubre de 2008.

${ }^{23}$ Testimonio del presidente de esa época de la JAC, Luis Arturo Holguín. Tomado de" ¿̇Esto es la Independencia? Un barrio que le falta mucho pero que se ve el avance. Periódico El Colombiano, 9 de octubre de 1999, pág. 1B 
${ }^{24} \mathrm{En}$ : "¿Esto es la Independencia? Un barrio que le falta mucho pero que se ve el avance. Periódico El Colombiano, 9 de octubre de 1999, pág. 1B.

${ }^{25}$ Instituto Popular de Capacitación.( 2005 ) Informe sobre el estado actual de los derechos humanos en la comuna 13 de la ciudad de Medellín. en:

www.kolko.de/downloads/IPC_comuna13_2005.rtf.

${ }^{26}$ Proyectos para el fortalecimiento de la convivencia. en:

http://www.fundacionapoye.org/php/ consulta 25 noviembre 2008.

${ }^{27}$ Testimonio de un líder comunitario de la 13 en un taller sobre SPD.

${ }^{28}$ Cortados: desconectados de 2 hasta 6 meses.

${ }^{29}$ Suspendidos: desconectados de más de 7 meses

${ }^{30}$ Caso recogido el 25 de marzo de 2008.

${ }^{31}$ Caso recogido el 22 de junio de 2007.

${ }^{32}$ Caso recogido el 12 de abril de 2008.

${ }^{33}$ Testimonio de una desconectada del barrio.

${ }^{34}$ Respuesta al Derecho de Petición presentado ante las EPM, radicado 01426015 del 2 de abril del 2008.

${ }^{35}$ Plan de Desarrollo Comuna 13. "SEMBRANDO PARA EL FUTURO Y DESARROLLO INTEGRAL"

${ }^{36}$ Datos procesados por la unidad de Clasificación Socioeconómica y Estratificación, de Planeación municipal. Respuesta a través de derecho de petición presentado a la Alcaldía de Medellín, con radicado 200900086512 del 4 de marzo de 2009.

${ }^{37}$ Caso recogido el 22 de junio de 2007. Barrio El Salado.

${ }^{38}$ Caso recogido el 25 de marzo de 2008. Barrio Independencias I.

${ }^{39}$ Caso recogido el 22 de junio de 2007. Barrio Veinte de Julio.

${ }^{40}$ Caso recogido el 25 de marzo de 2008. Barrio Altos de la Virgen.

${ }^{41}$ Caso recogido el 7 de septiembre de 2008. Barrio Nuevos Conquistadores

${ }^{42}$ Instituto Popular De Capacitación.( 2005 ) Informe sobre el estado actual de los derechos 
humanos en la comuna 13 de la ciudad de Medellín. En: www.kolko.de/downloads/IPC_comuna13_2005.rff.

${ }^{43}$ Salgado, Carlos. "En la comuna 13 el agua genera disputa". El Colombiano, 9 de octubre de 2006. Pág. $10^{\circ}$.

${ }^{44}$ lbídem.

${ }^{45}$ Personería de Medellín. Informe: La situación de los derechos humanos en la ciudad de Medellín durante el año 2007. 